\title{
In vitro Plant Regeneration through Somatic Embryogenesis in Medicinally Important leaf explants of Coleus forskohlii Briq.
}

\author{
C. GOPI*, M.D.ROSE MARY ${ }^{1}$ \\ Department of Botany, Cardamom Planters' Association College, Bodinayakanur - 625 513, Tamil Nadu, \\ INDIA, E-mail:drcgopi@gmail.com \\ ${ }^{1}$ Mary Matha Mat. Hr. Sec. School, CMI Centre, Madurai Road, Theni- 625 531, Tamil Nadu, INDIA, E-mail \\ mdrosemary@gmail.com
}

\begin{abstract}
High-frequency somatic embryogenesis and complete plant regeneration from leaf explants of Coleus forskohlii Briq had been established. The influence of plant growth regulators (PGRs) on the frequency of somatic embryogenesis and plant regeneration were studied. Murashige and Skoog (MS) medium supplemented with 2,4-dichlorophenoxyacetic acid (2,4-D) alone or both with 6-benzylaminopurine (BAP), were superior for somatic embryogenesis. Primarily, embryogenic callus was initiated from leaf explants of young plant on MS medium supplemented with 2,4-D $\left(1.0 \mathrm{mgl}^{-1}\right)$, 3\% sucrose and 0.9\% agar in three weeks. Embryogenic callus transferred on 2,4-D and BAP-supplemented medium favored induction of embryos in advance as compared to that on 2,4-D alone supplemented medium. The highest frequency (80\%) of direct somatic embryogenesis was obtained in the combination of BAP $(1.0 \mathrm{mg} / \mathrm{l})$ and 2,4-D $(0.5 \mathrm{mg} / \mathrm{l})$. Eighty percent of the embryos underwent maturation and conversion to plantlets upon transfer to half-strength MS medium having $\alpha$-naphthaleneacetic acid (NAA), with BAP. Embryo-derived plantlets were transferred onto specially made plastic cup containing soilrite followed by their transfer to the garden soil. Survival rate of the plantlets under ex vitro condition was $80 \%$.
\end{abstract}

Key words: Coleus forskohlii Briq, Leaf explants, Somatic embryogenesis, Regeneration, etc.

\section{Introduction}

The Indian herb Coleus forskohlii Briq, (Lamiaceae) commonly called as coleus plant is a naturally occurring perennial, aromatic, tuber crop. It is growing wild in India and also found in dry slopes at an altitude between $300 \mathrm{~m}$ and $800 \mathrm{~m}$ above sea level in parts of Eastern and Southern Asia and also in Africa (Souza and Shah 1988). C. forskohlii has been used as an important folk medicine in India. Forskolin, a labdane diterpene, is a major active compound isolated from tuberous roots of C. forskohlii (Bhat et al., 1977). Forskolin has multifaceted pharmacological effects that have been linked to its role as an activator of adenylate cyclase. Based on its pharmacological actions, forskolin appears to be well indicated in conditions such as eczema (atopic dermatitis), asthma, psoriasis, cardiovascular disorders and hypertension, where decreased intracellular cAMP level is believed to be a major factor in the development of the disease process (Narayanan et al., 2002). The production of forskolin is completely dependent on the commercial collection of wild and cultivated plants in India (Yanagihara et al., 1996).

In many plant species, regeneration of plants from callus tissue, especially highly totipotent embryogenic callus, has been recognized as one of the essential techniques for micropropagation and biotechnological applications. Plants are unique in their ability to produce somatic embryos (Gray, 1989). Somatic embryogenesis has been recognized as the efficient method for in vitro mass propagation of plants (Parrot et al., 1991 Gray \& Purohit 1991; Durzan \& Durzan, 1991; Gopi, and Ponmurugan 2006; Gopi, et al., 2006). Therefore, the interest in using these techniques for rapid and large-scale propagation of medicinal and aromatic plants has been significantly increased (Sahoo et al., 1997).

In the present research, C. forskohlii were taken to study somatic embryogenesis and complete plant regeneration. Generally, C. forskohlii is conventionally propagated by the seed germination and stem cutting. The problem associated with conventional method of propagation is that very poor germination rate of seeds and cuttings takes more than a month time to get sufficient rooting. In this experiment, we describe a reproducible protocol for rapid multiplication of $\mathrm{C}$. forskohlii via somatic embryogenesis, using young leaf explants were studied.

\section{Materials and Methods}

Young leaves of Coleus forskohlii explants were collected from two years old-field grown mature plants, cut into 1.0 to $2.0 \mathrm{~cm}$ segments and used for induction of embryogenic callus formation. Explants were washed thoroughly under running tap water for $30 \mathrm{~min}$ and treated with a surfactant, Tween 20 (10 drops per $100 \mathrm{ml}$ of sterilized distilled water). Later these explants were surface sterilized with $0.1 \%$ mercuric chloride 
$(\mathrm{w} / \mathrm{v})$ for $5 \mathrm{~min}$ and washed thrice using sterilized distilled water. Under aseptic conditions, explants were inoculated on basal MS (Murashige and Skoog, 1962) medium containing 3\% (w/v) sucrose, supplemented with different concentrations and combinations of 2,4 - dichlorophenoxyacetic acid (2.4-D), 6-benzylaminopurine (BAP: 0.0, 0.25, 0.51 .0 and $2.0 \mathrm{mg} / \mathrm{l}$ ), kinetin (KN: 0.0, 0.25, 0.51 .0 and $2.0 \mathrm{mg} / \mathrm{l}$ ), indole-3-acetic acid (IAA) or indole-3-butyric acid (IBA) $(0.0,0.10,0.25,0.5$ and $1.0 \mathrm{mg} / \mathrm{l})$ for direct embryogenesis, plant regeneration and root induction. The $\mathrm{pH}$ was adjusted to 5.8 prior to the addition of $0.8 \%$ agar and autoclaved at $121^{\circ} \mathrm{C}(1.06$ $\mathrm{kg} / \mathrm{cm} 2)$ for $15 \mathrm{~min}$. Cultures were then incubated at $26 \pm 2^{\circ} \mathrm{C}$ with a 16 -h photoperiod by cool white fluorescent tubes and $70-75 \%$ relative humidity.

For root induction, separated shoots were transferred to half strength MS basal medium supplemented with different concentrations of IAA and/or IBA $(0.0,0.25,0.50$ and $1.0 \mathrm{mg} / \mathrm{l})$ and $2 \%(\mathrm{w} / \mathrm{v})$ sucrose. Rooted plantlets were thoroughly washed to remove the adhering gel and planted specially made plastic cup containing soilrite and kept in the greenhouse for acclimatization.

Twenty cultures were used per treatment and each experiment was repeated at least three times. Percentage of success was scored four weeks after culture. Data collected were statistically analyzed and results presented in the tables.

\section{Induction of callus culture}

\section{Results and Discussion}

Leaf explants from two years old-field grown plants of $\mathrm{C}$. forskohlii were cultured on MS medium with various levels $(0.0,0.25,0.51 .0$ and $2.0 \mathrm{mg} / \mathrm{l})$ of 2,4-D alone and in combination with BAP for induction of callus. After 3 weeks of culture incubation indicated medium with high concentration 2,4-D alone upto $1.0 \mathrm{mg} / 1$ showed a remarkable callus formation. The calli obtained form this medium was faster growing, delicate, mostly spongy, and white creamy in colour (Table-1). While culturing in media amended with 2,4-D and BAP combination, data showed that calli were compact and yellow to pale green in colour with high frequency of callus formation at low concentration of 2,4-D $0.5 \mathrm{mg} / \mathrm{l}$ (Table-1). The highest callus induction was $80 \%$ at the end of fourth weeks. It was recorded on medium supplemented with $0.5 \mathrm{mg} / \mathrm{l}$ of 2,4-D and $1.0 \mathrm{mg} / \mathrm{l}$ of BAP. Similar combination of auxin with cytokinin for callus induction has been reported by Dode et al., (2003) \& Gopi, and Ponmurugan (2006). Our studies also accordance to Yasmin et al., (2001) and further reveal that 2,4$\mathrm{D}$ and BAP combination is essential for the compact green callus induction for somatic embryogenesis. On the other hand, Rahman et al., (2004) reported that the callus induction from leaf base as explant of Kaempferia galanga using $2.4 \mathrm{D}$ at $1.5 \mathrm{mg} \mathrm{l}-1$ with $\mathrm{BA}$ at $1.0 \mathrm{mg} \mathrm{l}^{-1}$.

Callus obtained from above mentioned medium was used to investigate the influence of growth regulators on the induction of somatic embryogenesis.

\section{Somatic Embryogenesis from the subcultured callus}

Induction of somatic embryogenesis from leaf callus was tried on MS medium with various concentrations of BAP+NAA+KN (Table 2). According to Godbole et al., (2002), the 2,4-D and BAP combinations was essential for initial culture establishment for callusing and subsequently, elimination of 2,4-D and a corresponding increase of BAP concentration induced somatic embryogenesis. Embyogenic potentialities of the callus showed difference to some extend which depending on the growth regulators supplements (Table 2).

In media, all the concentration of BAP and NAA combination showed that somatic embryogenesis started from the leaf callus after 3 weeks of subculturing. However, MS medium containing selected concentration of $1 \mathrm{mgl}^{-1}$ induced further somatic embryoids differentiation. The presence of both BAP and KN in this medium drastically improved the development of the embryos and allowed to obtain whole plantlets in 3-4 weeks (Fig. 1). Also noted that, root initiation started simultaneously from these well developed shoot from third week onwards since medium supplemented with NAA (Fig. 1). Similarly works of somatic embryogenesis induced from leaf explant of Stevia rebaudiana was reported by Filho et al., (1993) and Somatic embryogenesis and plant regeneration from leaf callus of Ocimum basilicum L., by Gopi, and Ponmurugan (2006).

The maximum percentage of embryogeneic callus was formed as embryos which recorded as $72 \%$. It was achieved on medium supplemented with in the combination of BAP $\left(1.0 \mathrm{mgl}^{-1}\right)+\mathrm{NAA}\left(1.0 \mathrm{mgl}^{-1}\right)+\mathrm{KN}(0.5$ $\mathrm{mgl}^{-1}$ ). The height number of somatic embryos per culture was $28.5 \pm 2.19$ (Fig. 1). Earlier report on complete plant regeneration via embryogenesis was observed on callus derived from leaf explant of Centella asiatica $\mathrm{L}$ using 4.52 $\mu \mathrm{M}$ 2,4-D or $5.37 \mu \mathrm{M} \alpha \mathrm{NAA}$, both with $2.32 \mu \mathrm{M}$ KN by Martin, K. P., (2004) and Mangefera indica using $1.0 \mathrm{mg} \mathrm{l}^{-1}$ 2, 4-D + $1.0 \mathrm{mg} \mathrm{l}^{-1} \mathrm{NAA}+1.0 \mathrm{mg} \mathrm{l}^{-1} \mathrm{KN}$ by Ara et al., (2004).

Fully developed plants were separated from cultures and washed thoroughly with running tap water then established in small plastic pots with a view to easy handling and maintenance during acclimatization and transplantation. About $85 \%$ of the plantlets were established well under ex vitro conditions when they were initially transferred onto soilrite mixture. 
The present investigation may be concluded that it is a first and highly effective method of propagation of C. forskohlii. Beside this, the regenerative potential of leaf discs into embryos can be a reliable tool for Genetic Engineering studies.

\section{Acknowledgement}

Authors are thankful to the Management and the Principal for providing the facility for the present study at Department of Botany, Cardamom Planters' Association College, Bodinayakanur - 625 513, Tamil Nadu, INDIA

\section{References}

[1]. Ara, H., Jaiswal. U., Jaiswal. V.S., 2004. An improved method of proliferation of proembryogenic calli of mangefera indica L. var. Amrapali for scal-up of somatic embryo production. Indian J. Biotechnol. 3, 229-234.

[2]. Begum. F., Amin. M.N., Azad, M.A.K., 2000. In vitro clonal propagation of Holy Basil - Ocimum sanctum L. Plant Tissue Cult. 10 : $31-37$.

[3]. Bhat. S.V., Bajqwa. B.S., Dornauer. H., De Scousa. N.J., Fehlhabar. H.W., 1977. Structures and stereochemistry of new labdane diterpenoids from Coleus forskohlii Briq. Tetrahedron Lett, 18:1669-1672.

[4]. De Souza. N.J., Shah. V., 1988. Forskolin - an adenylate cyclase activating drug from an Indian herb. In: Wagner H, Hikino H, Farnsworth NR, eds. Economic and Medicinal Plant Research Volume 2, London: Academic Press.

[5]. Dode, L.C., Bobrowski, V.L., Braga, E.J.B., Seixas, F.K., Schunch, W., 2003. In vitro propagation of Ocimum basilicum L. Maringa, 25, 435-437.

[6]. Durzan. D.J., Durzan. P.E., 1991. Future technologies: model-reference control systems for the scale-uo of embryogenesis and polyembryogenesis in cell suspension cultures. In: Debergh. P.C., Zimmerman. R.H., (Eds) Micropropagation. Kluwer, Academic Publ., Dordrecht. Pp 389-423.

[7]. Filho, J.C.B., Hasimoto, J.M., Viera, L.G.E., 1993. Induction of somatic embryogenesis from leaf explant of Stevia rebaudiana. R. Bras. Fisol. Veg. 5, 51-53.

[8]. Godbole, S., Sood, A., Thakur, R., Sharma, M., Ahuja, P.S., 2002. somatic embryogenesis and its conversion into plantlets in a multipurpose bamboo, Dendrocalamas hamiltonii nees et Arn. Ex Munro. Current Science, 83, 885-889.

[9]. Gopi, C., and Ponmurugan, P., 2006. Somatic embryogenesis and plant regeneration from leaf callus of Ocimum basilicum L., Journal of Biotechnology, 126 (2), 260-264.

[10]. Gopi, C., Nataraja Sekhar, C., Ponmurugan, P., 2006. In vitro multiplication of Ocimum gratissimum L. through direct regeneration, African Journal of Biotechnology, 5(9), 723-726.

[11]. Gray, D. J. 1989. Effects of dehydration and exogenous growth regulators on dormancy, quiescence and germination of grape somatic embryos. In Vitro Cell. Dev. Biol. 25:1173-1178.

[12]. Gray. D.J., Purohit. A.S., 1991. Somatic embryogenesis and development of synthetic seed technology. Critical Reviews in Plant Science. 10:33-61

[13]. Martin, K. P., 2004. Plant regeneration through somatic embryogenesis in medicinally important centella asiatica 1. In Vitro Cellular and Development Biology - Plant, 40(6), 586-591.

[14]. Murashige, T., Skoog, F., 1962. A revised medium for rapid growth and bioassays with tobacco tissue cultures. Physiol. Plant. 15, 473-497.

[15]. Narayanan. P., Laddha. K.S., Akamanchi. K.G., 2002. Histochemical localization of forskolin and other terpenoids in Coleus forskohlii. Current Science, 83(8), 945-946.

[16]. Parrot. W.A., Merkle. S.A., Williams. E.G., 1991. Somatic enbryogenesis:Potential for use in propagation and gene transfer systems. In: Murray DR (Eds) Advanced Methods in Plant Breeding and Biotechnology. CABInternational, Oxford. Pp 158-200.

[17]. Rahman, M.M., Amin, M.N., Ahamed, T., Ali, M.R., Habib, A. 2004. Efficient plant regeneration through somatic embryogeneisis from leaf based-derived callus of Kaempferia galangal L. Asian J. Plant Science 3, 675-678.

[18]. Sahoo, Y., Remien, Y.N., Yao, R.S., 1997. In vitro clonal propagation of an aromatic medicinal herb Ocimum basilicum L. (sweet basil) by axillary shoot proliferation. In vitro Cell. Devel. Biol. Plant, Largo, 33, 293-296.

[19]. Yanagihara. H., Sakata. R., Minamia. H., Tanaka. H., Shoyamaav. Y., Murakamib. H., 1996. Immunoaffinity column chromatography against forskolin using an anti-forskolin monoclonal antibody and its application. Analytica Chimica Acta 335: 6370 .

[20]. Yasmin, R., Javid, F., Arfan, M., 2001. Somatic embryogenesis in callus of wheat Triticum aestivum L., International Journal of Agriculture Biology, 03, 163-166.

Table 1:

Effects of different concentrations of 2,4-D and in combination with BAP for callus induction from leaf explant of C. forskohlii.

\begin{tabular}{|c|c|c|c|}
\hline $\begin{array}{c}\text { Growth regulators } \\
\left(\mathrm{mg} / \mathrm{L}^{-1}\right)\end{array}$ & $\begin{array}{c}\text { Percentage of explant } \\
\text { induced callus }\end{array}$ & Callus colour and morphology & $\begin{array}{c}\text { Degree of } \\
\text { callus response }\end{array}$ \\
\hline $\mathbf{2 , 4 - D \text { alone }}$ & 55 & $\mathrm{~W}$ & $\mathrm{a}$ \\
0.2 & 75 & $\mathrm{Cr}+\mathrm{S}$ & $\mathrm{c}$ \\
1.0 & 85 & $\mathrm{Cr} \mathrm{W}+\mathrm{S}$ & $\mathrm{c}$ \\
2.0 & 65 & $\mathrm{~W}+\mathrm{S}$ & $\mathrm{b}$ \\
$\mathbf{2 , 4 - D + B A P}$ & & & $\mathrm{c}$ \\
$0.5+0.5$ & 70 & $\mathrm{PG}$ & $\mathrm{c}$ \\
$0.5+1.0$ & 80 & $\mathrm{G}$ & $\mathrm{b}$ \\
$0.5+2.0$ & 75 & $\mathrm{GG}$ & $\mathrm{b}$ \\
$1.0+0.5$ & 65 & $\mathrm{G}$ & $\mathrm{a}$ \\
$1.0+1.0$ & 65 & $\mathrm{G}$ & \\
$1.0+2.0$ & 65 & & \\
\hline
\end{tabular}

${ }^{a}$ slight callusing; ${ }^{b}$ More callusing; ${ }^{\mathrm{c}}$ profuse callusing

W: White; Cr: Creamy; PG: Pale green; G: Green; S: Spongy

20 explants were maintained in each treatment and data were recorded upto 7 weeks of culture 
Table 2: Effects of different concentrations and combination of BAP + KN + NAA for somatic embryogenesis*.

\begin{tabular}{|c|c|c|}
\hline $\begin{array}{c}\text { Growth regulators } \\
\left(\mathrm{mg} / \mathrm{L}^{-1}\right)\end{array}$ & $\begin{array}{c}\text { \% of somatic Embryogenic } \\
\text { potential of callus }\end{array}$ & $\begin{array}{c}\text { No. of somatic } \\
\text { embryos/culture }\end{array}$ \\
\hline BAP+NAA & 50 & $10.2 \pm 0.12$ \\
$1.0+5.0$ & 55 & $10.5 \pm 0.14$ \\
$1.0+1.0$ & 55 & $10.3 \pm 0.13$ \\
$1.0+2.0$ & 70 & $24.5 \pm 2.12$ \\
BAP+NAA+KN & 80 & $33.2 \pm 2.20$ \\
$1.0+1.0+0.2$ & 75 & $30.3 \pm 2.15$ \\
$1.0+1.0+0.5$ & 60 & $21.2 \pm 1.15$ \\
$1.0+1.0+1.0$ & 65 & $22.0 \pm 1.16$ \\
$2.0+1.0+0.2$ & 65 & $21.1 \pm 1.18$ \\
$2.0+1.0+0.5$ & 45 & $10.1 \pm 0.06$ \\
$2.0+1.0+1.0$ & 55 & $10.5 \pm 0.15$ \\
$3.0+1.0+0.2$ & 55 & $10.2 \pm 0.16$ \\
$3.0+1.0+0.5$ & & to \\
$3.0+1.0+1.0$ & & six
\end{tabular}

culture.

* 20 explants were maintained in each treatment and data were recorded up to six weeks of

Figure (a-i) In vitro Plant Regeneration through Somatic Embryogenesis of Coleus forskohlii on solid MS medium with BAP $1.0 \mathrm{mg} \mathrm{l}^{-1}$, NAA $1.0 \mathrm{mg} \mathrm{l}^{-1}$ and $\mathrm{KN} 0.5 \mathrm{mg} \mathrm{l}^{-1}$

a-c, Establishment of embryogenic tissue from the leaf callus

b-g, Development of shoots from embryoids

$\mathrm{h}$, Shoots and roots development and elongation of plantlets

i. Well-developed complete plants in MS + BAP $(0.5 \mathrm{mg} / \mathrm{l})+\mathrm{NAA}(0.5 \mathrm{mg} / \mathrm{l})$

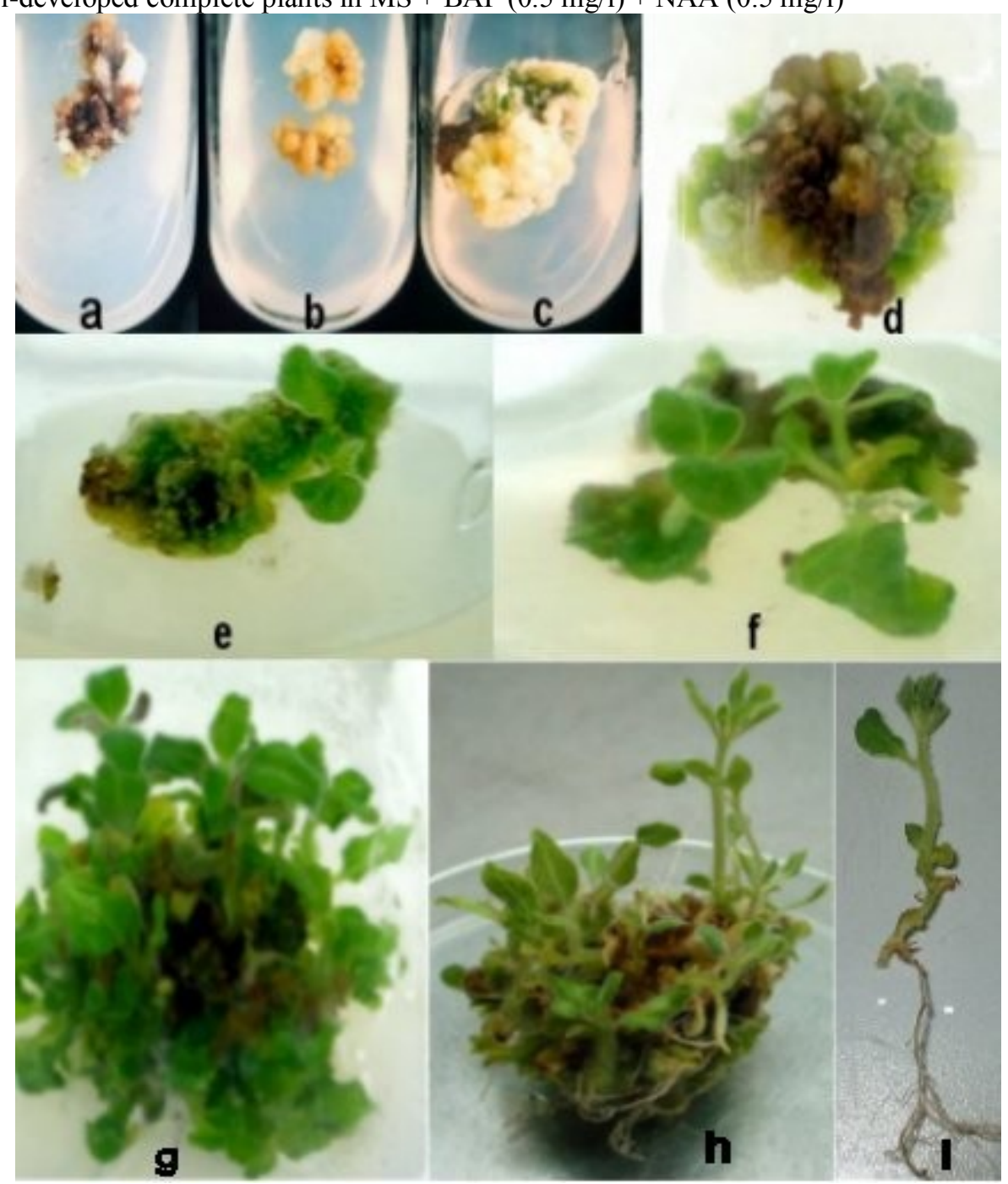

